\title{
Passive Optical Networks Beneficial to Cloud Computing
}

\section{Ankit Chandle Deptt. Of C.S.E Shoolini University Solan India}

\author{
Avtar Singh \\ Deptt. Of C.S.E \\ Shoolini University \\ Solan India
}

\author{
Naresh Kumar \\ Deptt. Of E.C.E \\ Shoolini University, \\ Solan India
}

\author{
Anju Bala \\ Deptt. Of C.S.E \\ Shoolini University, \\ Solan,India
}

\begin{abstract}
The focus of the paper is on BPON (Broadband Passive Optical Network) with Metropolitan Area Network in Cloud user perspectives. The model focuses on effect of jitter on cloud computing environment with PON. The study show that data transfer rate with the help of jitter on cloud at different length for multimedia file in wired (optical) network is efficient.
\end{abstract}

\section{Keywords}

CBN (Cloud Based Network),CEN( Cloud Enabled Network), PON (Passive Optical Network), OLT (Optical Line Terminal), ONT (Optical Network Terminal), ONU (Optical Network Unit), ATM (Asynchronous transfer mode).

\section{INTRODUCTION}

The cloud is transforming IT infrastructure and making it possible for any size business to adopt and afford enterpriseclass apps, computing and storage without the cost, complexity and constraints of traditional networks [1]. As we know that cloud computing is internet based technology. Today Cloud demands high speed internet to provide services to users as upload and download multimedia files are more demanded. Cloud doesn't depends on single network but it uses hybrid network that is wired or wireless LAN, MAN, WAN and hybrid topology . Various user and distant recourses utilized by cloud act as distributed system between numbers of system spread all over the world .multimedia files need high bandwidth to upload and download especially video file because consumers watch multiple HDTV channels often on several TVs in the same household at the same time.

Fiber optics is used for high speed data transfer as G.983 series of ITU-T broadband PON (BPON). Design and deployment activities for FTTH (fiber-to-the-home) and FTTP (fiber-to-the-premises) access networks are on the rise in order to support the increasing demands and delivery of new multimedia services to the customer premise such as interactive video, voice and high-speed Internet [2].

\section{CLOUD NETWORK}

Cloud networking is a new networking paradigm for building and managing secure private networks over the public Internet by utilizing global cloud computing infrastructure. In cloud networking, traditional network functions and services including connectivity, security, management and control, are pushed to the cloud and delivered as a service. There are two categories within cloud networking: Cloud-Enabled Networking (CEN) and Cloud-Based Networking (CBN) [3]. CEN moves management and certain aspects of control (such as policy definition) into the cloud, but keeps connectivity and packet-mode functions - such as routing, switching and security services - local and often in hardware.CBN only require an Internet connection and work over any physical infrastructure, wired or wireless, public or private. Cloud network is a hybrid network consisting of local area network, metropolitan area network, and wide area network even virtual machines along with provider and user perspectives as shown in Figure 1.

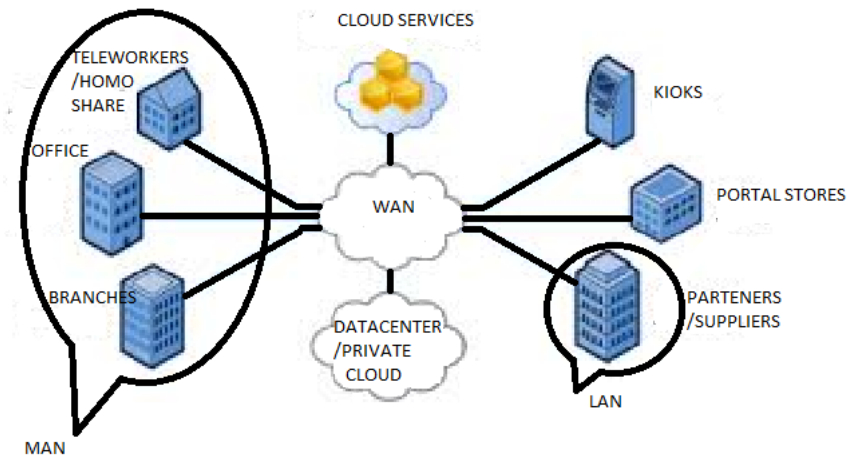

Figure 1 Cloud hybrid Network

Most cloud networks utilize per user or device subscription pricing, so there is little to no upfront costs and users pay-asyou-grow [4].

\section{BPON NETWORK}

Fiber-To-The-Home (FTTH) for broadband access applications may be considered as an effective solution for higher capacity access networks as optical fiber in telecommunications have huge capacity, small size, light in weight, very high bandwidth and immunity to electromagnetic interference etc [5]. There are many types of FTTH technologies; the most popular one is based on the concept of using a passive fiber distribution network known as a passive optical network (PON). FTTH employing PON access architecture is the accepted choice of delivery channel for triple-play services (voice, video and data) from service providers to the home and business users [6]. The APON format used by FSAN was accepted as an International Telecommunications Union (ITU) standard (ITU-T Rec. G.983.xseries). The ITU started releasing the G.983 series recommendations and amendments in1998. These deal with the broadband optical access systems based on BPONs. Passive optical networks (PONs) address the last mile of the communications infrastructure between the service provider's $\mathrm{CO}$, head end, or point of presence (POP) and business or residential customer locations [7]. The APON format 
developed by the FSAN alliance was used as the basis for an international standard released by ITU-TS (Rec. G. 983.x), designated by BPON (Broadband PON)[8-9]. This standard supports more broadband services, including high-speed Ethernet and video distribution. In a PON, the active optoelectronics are situated on either ends of the passive network. An optical line termination (OLT) device is installed in the central office (CO), and an optical network termination (ONT) device is installed on the other end, in or near each home or business site. Fiber distribution is done using a treeand-branch architecture. A single fiber connected to the OLT can be split up to 32 times and connected to multiple ONTs.

\section{SIMULATION WORK}

Current simulation model is a typical BPON FTTH design with 32 subscribers and 20-Km reach as represents in Figure 2 and perimeters are defined in Table 1 . The technique used in simulation is coarse wavelength division multiplexing (CWDM).
Table 1. Simulation attributes

\begin{tabular}{|c|c|c|}
\hline Attributes & \multicolumn{2}{|l|}{ Value } \\
\hline Data rate & \multicolumn{2}{|c|}{$1.25 \mathrm{~Gb} / \mathrm{s}$ downstream } \\
\hline Distance & \multicolumn{2}{|c|}{$20 \mathrm{Km}$} \\
\hline Subscribers & \multicolumn{2}{|l|}{32} \\
\hline \multirow[t]{2}{*}{ Splitter } & \multicolumn{2}{|c|}{$1: 4$ at $15 \mathrm{Km} \mathrm{SMF}$} \\
\hline & \multicolumn{2}{|c|}{$1: 8$ at $4.5 \mathrm{Km}$ form $1: 8$ splitter } \\
\hline ONT drop off Cables & \multicolumn{2}{|c|}{100 to 900 feet } \\
\hline Subcarrier multiplexed & \multicolumn{2}{|l|}{ 16-QAM } \\
\hline \multirow[t]{2}{*}{ Wavelength Range } & $\begin{array}{l}\text { Voice and } \\
\text { data }\end{array}$ & $1500 \mathrm{~nm}$ \\
\hline & Video & $1550 \mathrm{~nm}$ \\
\hline
\end{tabular}

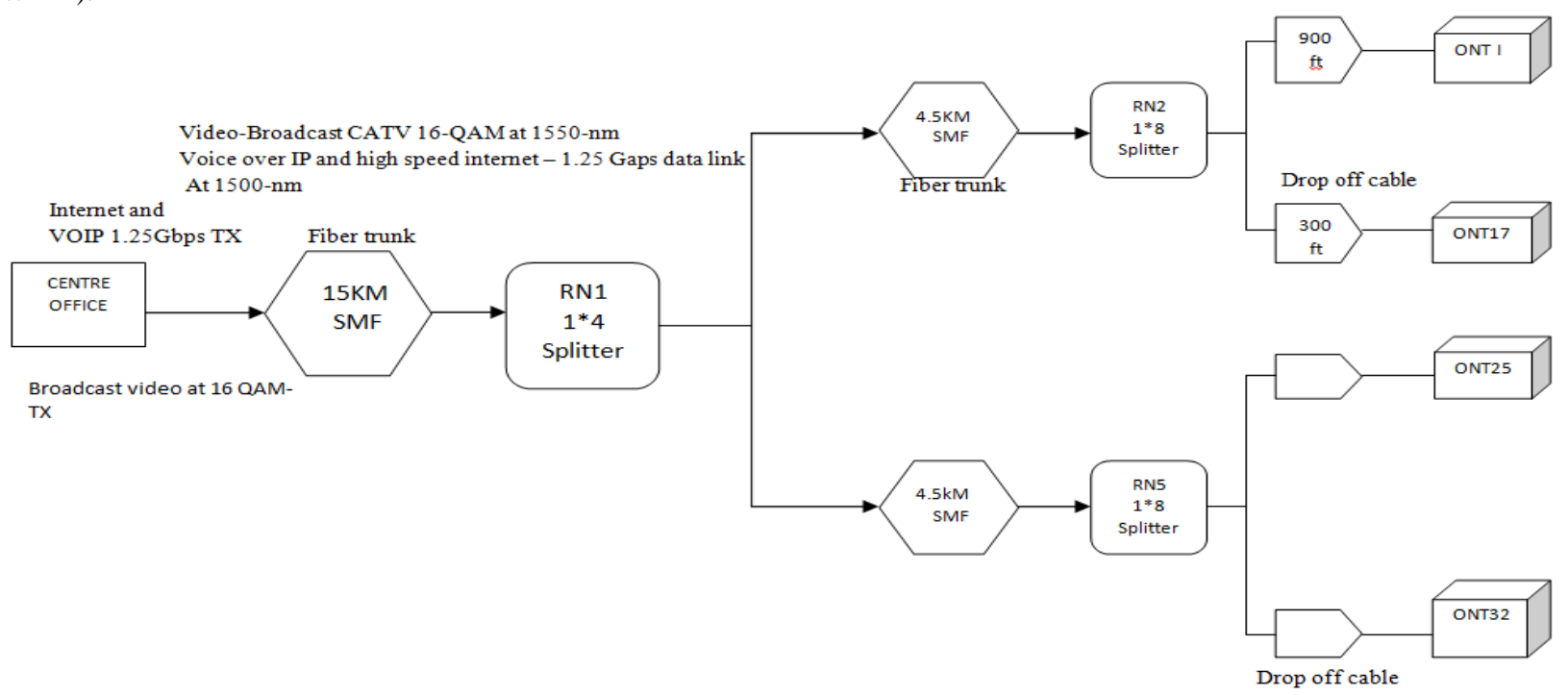

Fig 2: FTTH BPON systems

The triple-play (multimedia) service is realized as a combination of data, voice, and video signals. The voice component can be represented as VOIP service (voice over IP, packet-switched protocol), which is gaining popularity as an alternative to traditional PSTN (public switched telephone network) with POTS (plain old telephone service) at the customer end. A downstream link with one ONT unit attached at $10 \mathrm{Km}$ and $20 \mathrm{Km}$. The optical signal first de-multiplexed into data/voice and video components. The data component goes to the optical receiver. Jitter is the distortion in signal such as material losses, losses with length. Jitter is compared at different length with the help

of Output Spectrum, signal constellation diagram, eye diagram. Data transfer stream with Figure 3 shows the signal spectrum output from OLT with data/voice signal at $1500 \mathrm{~nm}$ and video signal at $1550 \mathrm{~nm}$ where distance is $0 \mathrm{Km}$ as fiber is not used. Figure 4 and Figure 5 describes the jitter at distance of $10 \mathrm{Km}$ and $20 \mathrm{Km}$ with output spectrum where transmission is done through OLT to ONT.

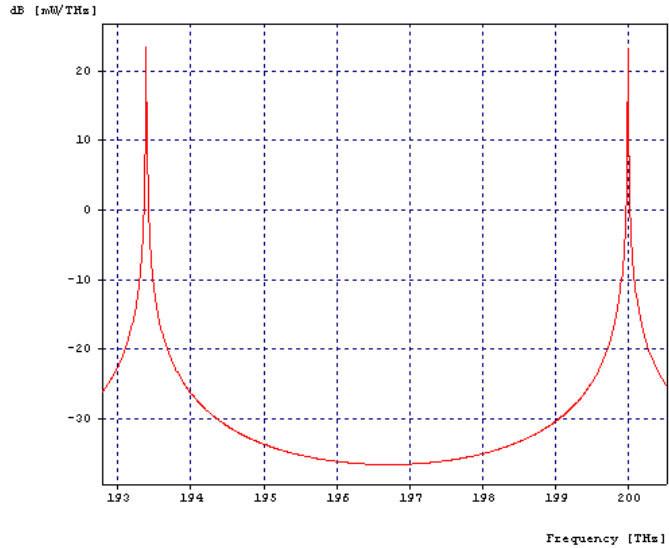

Fig 3: output spectrum for $\mathrm{CO}$ at $0 \mathrm{Km}$ 
AB $[\mathrm{min} / \mathrm{TH}=\mathrm{T}$

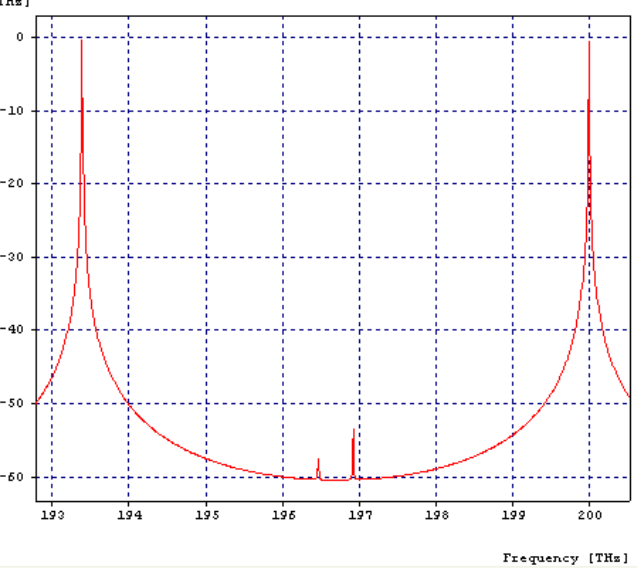

Fig 4: output spectrum at $10 \mathrm{Km}$

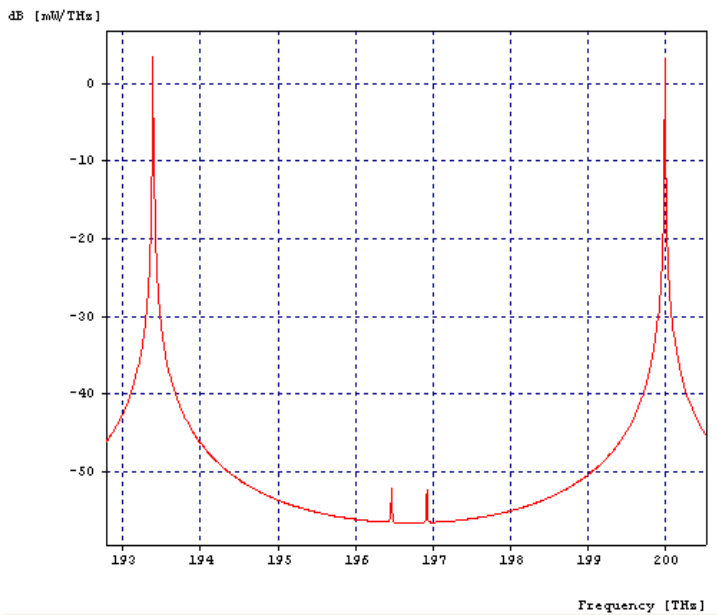

Fig 5: Output spectrum at $20 \mathrm{Km}$

Fig 6 demonstrates 4-level signal constellation plot for 16QAM encoder at CO.

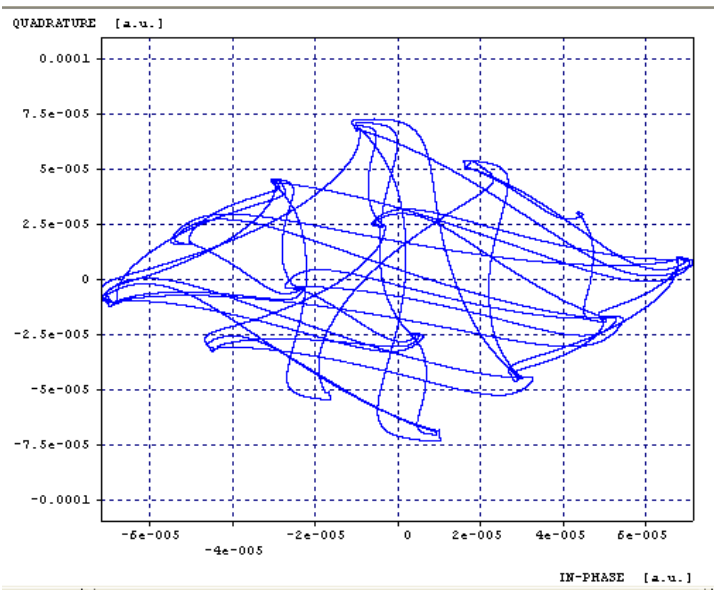

Fig 6: Signal constellations at $0 \mathrm{Km}$

The video component of the received signal enters 16 QAM decoder. Fig 7 demonstrates 4-level signal constellations plot for 16-QAM decoder at $10 \mathrm{Km}$ for ONT 1 and Figure 8 demonstrates 4-level signal constellations plot for 16-QAM decoder at $20 \mathrm{Km}$.

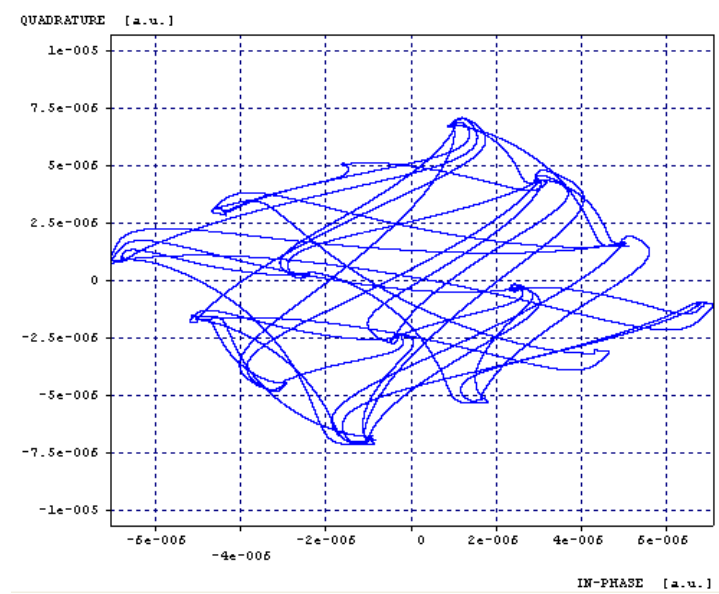

Fig 7: Signal constellations at 16-QAM encoder $10 \mathrm{Km}$

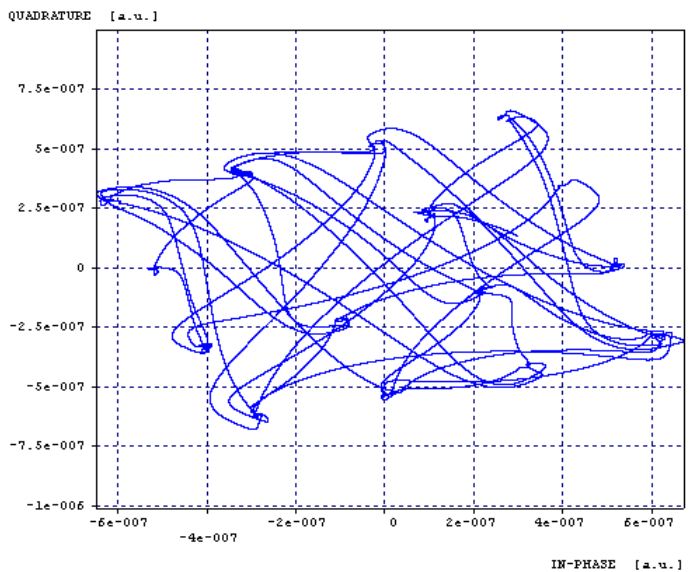

Fig 8: Signal constellations at 16-QAM encoder $20 \mathrm{Km}$

The eye diagram at the input to ONT $(0 \mathrm{Km})$ is shown at Fig 9 and Fig 10 , Fig 11 depicts receiver eye diagram at $10 \mathrm{Km}$ and $20 \mathrm{Km}$.

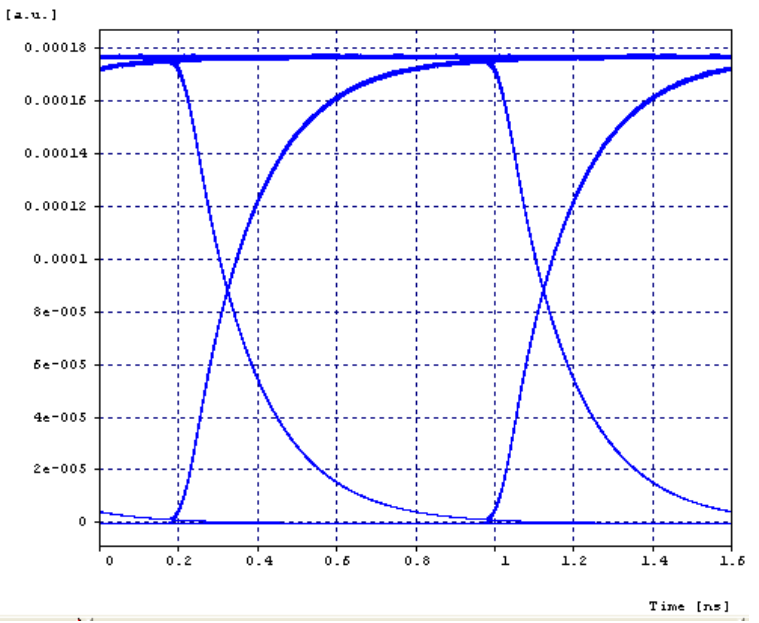

Fig 9: eye diagram ai input $\mathrm{CO}$ at $0 \mathrm{Km}$ 


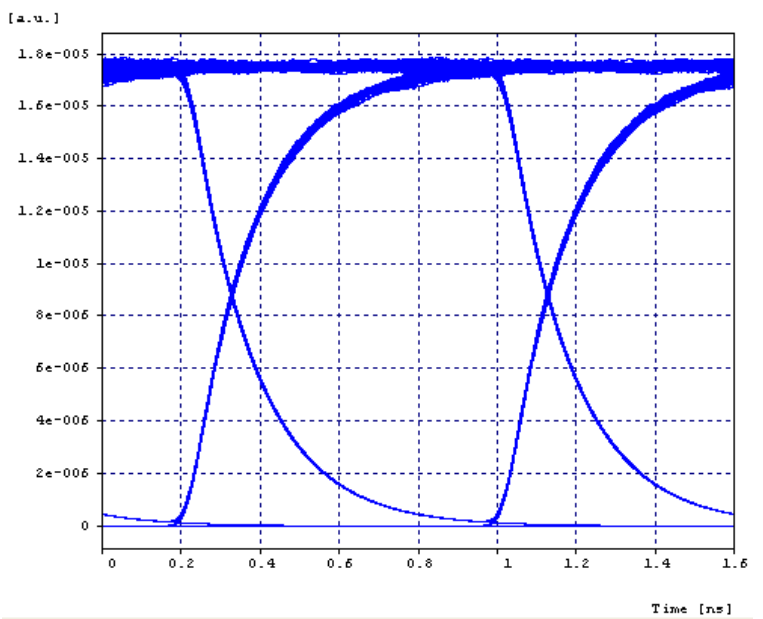

Fig 10: Receiver eye diagram at $10 \mathrm{Km}$

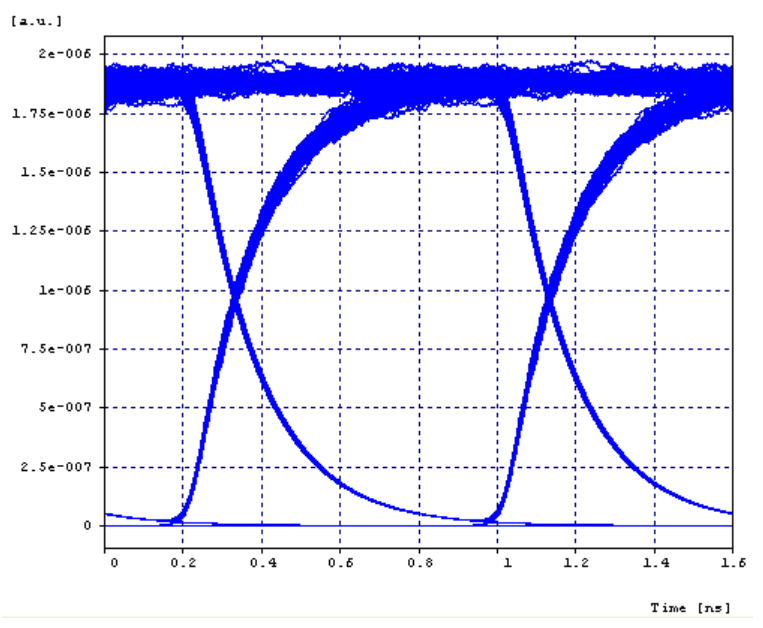

Fig 11: Recever eye diagram at $20 \mathrm{Km}$

Fig 12, Fig 13 and Fig 14 depicts multilevel eye pattern at 16QAM decoder at $0 \mathrm{Km}, 10 \mathrm{Km}$ and $20 \mathrm{Km}$.

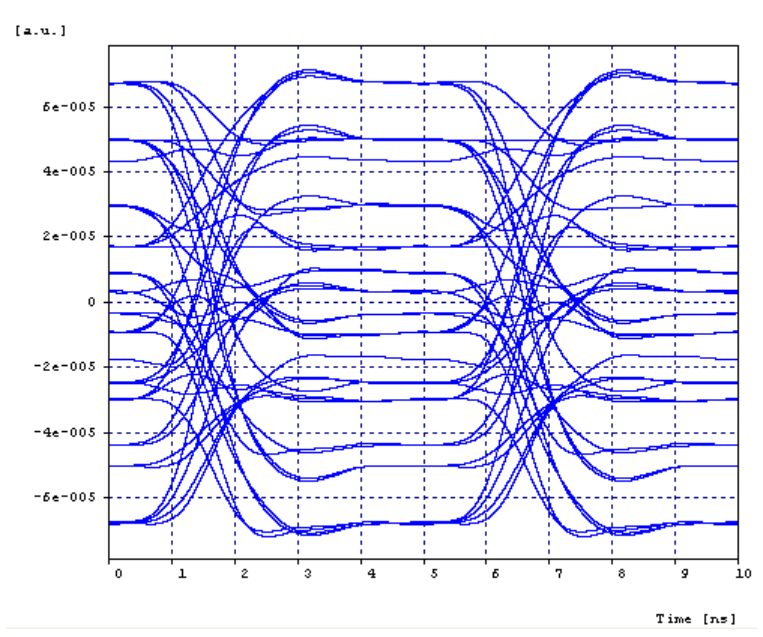

Fig 12: Eye-pattern at 16-QAM encoder

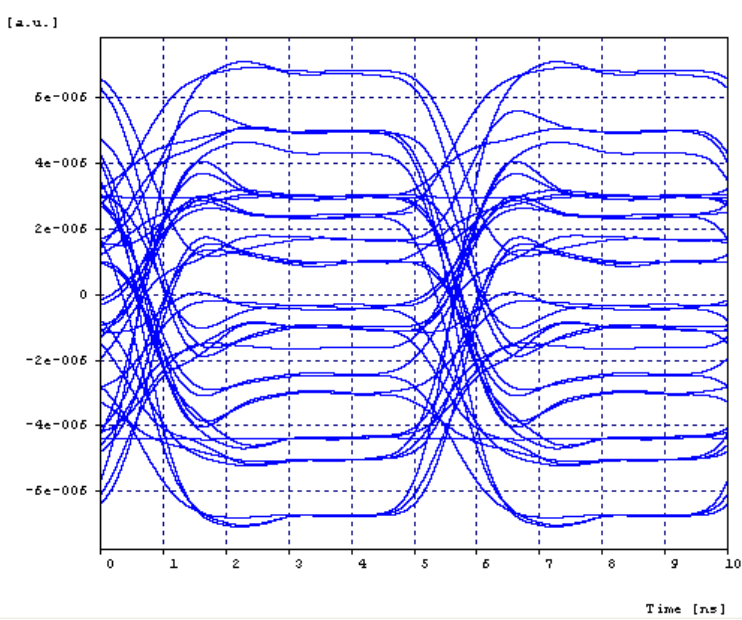

Fig 13: Eye-pattern at 16-QAM Decoder at $10 \mathrm{Km}$

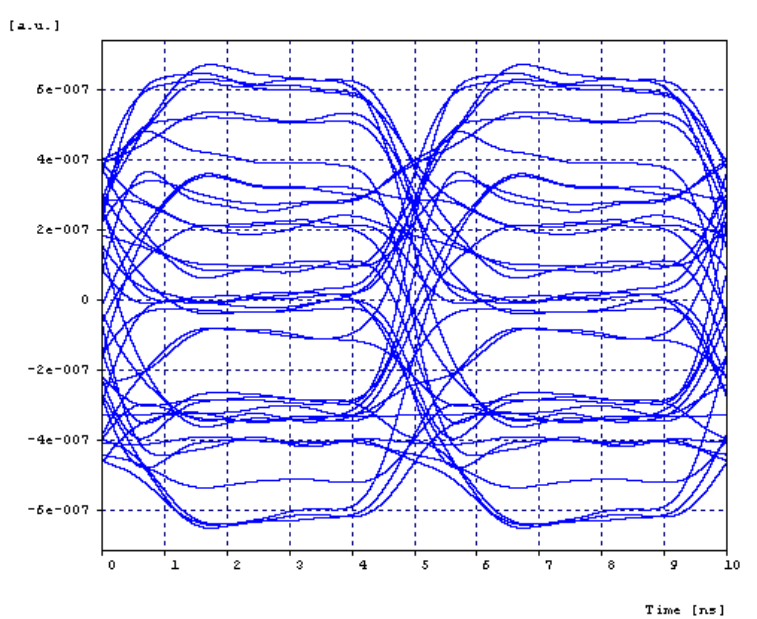

Fig 14: Eye-pattern at 16-QAM Decoder at $20 \mathrm{Km}$.

\section{CONCLUSION}

This paper targets the impact of cloud computing in BPON systems. It has been observed the performance on BPON at distance $0 \mathrm{Km}, 10 \mathrm{Km}$ and $20 \mathrm{Km}$ and concludes that is more suitable for $20 \mathrm{Km}$ for metropolitan network in cloud multimedia data. Thus enhance the internet speed for cloud user and video streaming will be better at speed $100 \mathrm{Mbps}$ per end user in $20 \mathrm{Km}$ area for MAN. BPON can overcome the high bandwidth for video streaming according to the need with less power as shown in simulation. Thus the result shows QoS increases with speed as time decrease. It has been concluded that near future, Live video streaming in cloud computing can be done efficiently for high definition, Online video play can be done very least buffering time, BPON network may be expended to long distance by adopting the proper frequency for data, audio and video file transmission with lesser jitter. Hence the quality of cloud computing can be enhanced for multimedia files in future for wide area networks 


\section{REFFERNCES}

[1] Mervat Adib Bamiah and Sarfraz Nawaz Brohi .Exploring the Cloud Deployment and Service Delivery Models. International Journal of Research and Reviews in Information Sciences (IJRRIS), Vol. 1, No. 3, (September 2011), 77-80.

[2] Lung, B. PON Architecture future proofs FTTH. J. Light wave Technology, vol. 16, October 1999, pp 104-107.

[3] Cervino, Politec. De Madrid, Madrid, Rodriguez,Trajkovska ,Mozo . Testing a Cloud Provider Network for Hybrid P2P and Cloud Streaming Architectures. Cloud Computing (CLOUD), 2011 IEEE International Conference, Washington, DC, (4-9 July 2011), $356-363$.

[4] Musa, Nejabati, Simeonidou. Performance analysis of hybrid network for cloud datacenter .Computer Science and Electronic Engineering Conference (CEEC), $20124^{\text {th }}$ Colchester (12-13 September 2012), 154 - 159.

[5] Zahid ,Hasoon, Bakarman, Shaari, .Implementing EDW in Point to multipoint optical access network for FTTH applications. Communications (MICC), 2009 IEEE 9th Malaysia International Conference, Kuala Lumpur (1517 December 2009), 371 - 375.
[6] Ramaswami, R. and Sivarajan, K. N. Optical Networks, a Practical Perspective. Morgan Kaufmann, San Francisco, 1998.

[7] George Lawton. Telecom Carriers Actively Pursue Passive Optical Networks. IEEE Computer Society, February 2005, Vol. 38, No. 2 , 19-21

[8] G. Parca, Ali Shahpari, V. Carrozzo, G.M. Tosi Beleffi, L.J.Teixeira .Broadband Free Space Optical Urban Links for Next Generation Infrastructures and Services. Transparent Optical Networks 15th International Conference on IEEE 2013, Cartagena (23-27 June 2013).

[9] P.B.Harboe and J.R.Souza, .Passive Optical Network: Characteristics, Deployment and Perspectives. IEEE Latin America Trabsaction, vol.11, no.4, (June 2013), 995-1000

[10] Dike,Ogbe .Optimizing the efficiency of Fiber-Optics Technology in Telecommunications system. Emerging \& Sustainable Technologies for Power \& ICT in a Developing Society (NIGERCON) (14-16 Nov. 2013), $135-142$.

[11] S Sujith and K G Gopchandran. A simulation study on DCF compensated SMF using OptSim.Ultra-Modern Telecommunications and Control Systems and Workshops (ICUMT), Moscow(18-20 Oct. 2010), 851 854. 